\title{
The Algorithm AND the CROWD: Considering THE MATERIALITY OF SERVICE INNOVATION ${ }^{1}$
}

\author{
Wanda J. Orlikowski \\ Sloan School of Management, Massachusetts Institute of Technology, 100 Main Street, \\ Cambridge, MA 02142 U.S.A. \{wanda@mit.edu\}
}

Susan V. Scott

Information Systems and Innovation Faculty, Department of Management, The London School of Economics and Political Science, Houghton Street, London WC2A 2AE UNITED KINGDOM \{s.v.scott@Ise.ac.uk\}

\begin{abstract}
This special issue acknowledges important innovations in the world of service and within this domain we are particularly interested in exploring the rise and influence of web-based crowd-sourcing and algorithmic rating and ranking mechanisms. We suggest that a useful way to make sense of these digital service innovations and their novel implications is to recognize that they are materialized in practice. We thus need effective conceptual and analytical tools that allow us to take materiality seriously in our studies of service innovation. To this end, we propose some theoretical ideas relating to a sociomaterial perspective, and then highlight empirically how this perspective helps us analyze the specific service materializations enacted through the algorithmic configuring of crowd-sourced data, and how these make a difference in practice to the outcomes produced.
\end{abstract}

Keywords: Algorithms, crowds, innovation, materiality, performativity, practice, sociomateriality

\section{Introduction}

The concepts of service and service innovation have attracted considerable recent attention in the fields of marketing and operations (Gustafsson and Johnson 2003; Rust and Chung 2006; Spohrer and Riecken 2006; Vargo and Lusch 2004, 2008). While manufacturing remains an important arena of economic activity, services have emerged as the main source of job creation in OECD countries (Bardhan et al. 2010; Sheenan 2006), accounting for approximately 80 percent of economic activity (NAE 2003). There is increasing talk of a service-based economy, with the services sector providing core infrastructures through which businesses compete and

\footnotetext{
${ }^{1}$ Michael Barrett, Elizabeth Davidson, Jaideep Prabhu, and Stephen L. Vargo were the accepting senior editors for this paper. Mike Chiasson served as the associate editor.
}

expand, domestically and globally. It is estimated that services account for 20 percent of international trade, challenging businesses to work across temporal, geographic and cultural boundaries. Working across such boundaries-in effect, engaging with different "service worlds" (Barrett and Davidson 2008; Bryson et al. 2004) — has heightened awareness that the ways in which service interactions, relationships, and encounters are structured matters (Gutek et al. 2000). As information systems become more central to the structuring of services, there is growing recognition that technology not only increases their scale, scope, and reach, but also shapes their design, delivery, and influence (Ramiller and Chiasson 2008).

Rouse and Baba (2006) note that accounts of work may be constructed from many different perspectives, each of which holds its own distinct value and each of which cuts the world in its own way: 
Engineering tends to see work in terms of the flow of physical items that are machined, assembled, and so on. Computing sees work as the flow of information to support the activities associated with work. Architecture views work in terms of the flow of people through built environments (p. 69).

They suggest that the field of information systems has a long tradition of systems thinking and sociotechnical approaches that recognize the social/cultural aspects of work in addition to the technological ones, emphasizing that

work organizations are not solely technical or rational systems designed to accomplish managerial goals, but they also embed natural or social systems whose characteristics extend beyond the rational and thus connect them with all other human social groups (p. 70).

Historically, sociotechnical systems were associated with the trade union movement and a theme of worker empowerment tempered the overall goal of joint optimization. Reengineering largely pushed ethical concerns and emancipatory politics to the background as the terms of information systems shifted from job enhancement to rationalization. Identifying discrete technical and social elements in order to optimize them-as epitomized by the original sociotechnical systems approach - thus shifted from improving performance through work-life enrichment to a drive for systems efficiency. Today, it is generally accepted that if service innovation is to be effective, we need to understand not only local work systems but also broader enterprise relationships and how to support them. Indeed, within information systems, some have proposed adopting a "services rather than traditional systems perspective" to understand contemporary technological practice (Mathiassen and Sorensen 2008, p. 313).

Much debate surrounds the question of how to effectively conceptualize and theorize service (Barrett and Davidson 2008). The service innovation literature has highlighted how boundaries between the categories of products and services have been blurred, emphasizing the importance of relationships and performances, and generating discussion about what should be labeled as service (Lovelock and Gummesson 2004; Rust and Chung 2006; Vargo and Lusch 2004, 2008). Motivating these discussions is a sense that

The dominant, goods-centered view of marketing not only may hinder a full appreciation for the role of services but also may partially block a complete understanding of marketing in general (Vargo and Lusch 2004, p. 2).
We would argue that this applies equally to the study of service-centered information systems.

The existing literature on services and service innovation has generated important insights into the dynamic and continuous interactions that shape the development and delivery of services. Our interest here is to extend these insights by arguing for the importance of materiality in service dynamics and, in particular, to draw attention to contemporary technological developments involving algorithmic transformations of crowd-sourced data. In the following sections we articulate the value of considering the materiality of services and consider potential conceptual insights that may be generated from a sociomaterial perspective. We then discuss some empirical cases in social media to explore how services are materialized in specific boundary-making and performative practices. We end with some considerations of possible future research directions.

\section{Calling out the Materiality of Services}

A key theme guiding the current discussions in this area is the notion that the conventional dominance of goods over services is no longer appropriate or useful (Vargo and Lusch 2004), prompting a move to reconceptualize products in terms of services (Gustafsson and Johnson 2002). Iconic examples highlight corporations, such as GE, IBM, Xerox, and Interface, undergoing a process of "servitization" in which they recategorize themselves from product companies to services groups. As Rust (1998, p. 107) writes,

most goods businesses now view themselves primarily as services, with the offered good being an important part of the service (rather than the service being an augmentation of the physical good).

A foray into the back-office realm of legal and regulatory contracts reveals that the move to "servitize" is reconfiguring not only design and logistics, but also infrastructures, boundaries, and power relations. These are evident, for example, in the shifts to outsourcing contracts that are transforming internal functions into interorganizational service relationships and in the rise of performance-related job contracts that are establishing internal markets premised on service relationships (Spohrer et al. 2007). In the field of Information Systems, important contemporary developments - including cloud, grid, and web services as well as smart, wearable, and mobile technologies - are involved in such transformations as contractually bound business grids, digital ecosystems, and 
on-demand and availability-based service level agreements. These service developments build upon and extend established core infrastructures and progressive institutionalization of standards (Bardhan et al. 2010; Chesbrough and Spohrer 2006; Tilson et al. 2010).

Most scholarship has recognized that for service to be effective, it must have meaning that comes from its embeddedness, and so our efforts focus on how to produce analyses that engage with the complexities of context. Chandler and Vargo (2011) emphasize the influence of context on value cocreation in services, while Ramiller and Chiasson (2008) suggest moving from discrete models of service to the notion of an "organizing vision" encompassing multiple contextually relevant discourses - regulatory, governmental, ethical, as well as commercial, technological, and entrepreneurial. They suggest that understanding broader organizing visions

helps define how people and their organizations think substantively about the possibilities while also lending normative force to the service innovation. In this way, public discourse can have an institutionalizing effect that helps to move the innovation toward a taken-for-granted-status, even as it serves as a resource in an organization's local sensemaking (p. 15).

We argue that what enacts this organizing vision, drawing the topology of concerns together, is practice. Practice perspectives focus on people's everyday doings, and examine the structural and interpersonal elements that produce and are produced in those doings (Feldman and Orlikowski 2011). Practices are understood to be constitutive, and as such both dynamic and ongoing. Practices are engaged in by people as part of the structuring processes through which institutions and organizations are produced, reinforced, and transformed over time (Giddens 1984). Adopting a practice perspective thus requires neither a choice between a macro or a micro level of analysis, nor a conflation of the two. Instead, it directs attention to how institutional phenomena are constituted in everyday activities, and how those everyday activities, in turn, are shaped by institutional influences and entailments.

As a focus of analysis, studying practice requires attending to recurrent, situated activities informed by shared meanings (Schatzki et al. 2001). On these grounds, we argue that a practice-based approach to studying service and service innovation would be particularly useful. Practices offer a valuable lens through which we can analyze shifts in service because they enable us to engage deeply with everyday activities and produce insights into value generation across multiple interests implicated in reconfiguring resources and restructuring relationships (Barrett and Davidson 2008; Chesbrough and Spohrer 2006; Vargo and Lusch 2004).

Many of the case studies, from sectors such as entertainment, hospitality, software, and logistics emphasize the reconceptualization of tangible products as intangible services, and place considerable importance on the reorganization of nonphysical assets and resources that accompany the shift to servitization. As Vargo and Lusch (2004, p. 15) argue,

The focus is shifting away from tangibles and towards intangibles, such as skills, information, and knowledge, and toward interactivity and connectivity and ongoing relationships.

We offer three extensions that build upon the current framing, foregrounding aspects that have been present but in the background to date. In particular, we want to focus on the constitutive role of practices in services, the materiality of services, and the performative consequences of services materialization.

First, services (and goods) are constituted in practice. While much of the early work in economics and marketing privileged a goods-orientation that tended to treat services as residual, this has now been replaced with a service-centered view that highlights exchange processes, the cocreation of value, and core competences. This is a valuable move, particularly given the shift to a service economy. However, it has tended to replace one dominant logic (that of goods and tangible resources) with another (that of service and intangible resources). As Vargo and Lusch (2008, p. 256) further note,

In S-D [service-dominant] logic, ... it is the knowledge and skills (competences) of the providers that represent the essential source of value creation, not the goods, which are only sometimes used to convey them. Thus, in S-D logic, goods are still important; however, service is superordinate.

Both the goods and service-dominant logics overlook the ways in which producing and consuming outputs - at the level of practices - are relatively similar, in the sense that they entail a range of activities, bodies, and artifacts. For example, the manufacture of a refrigerator and the writing of accounting software both involve human bodies engaged in an array of recurrent activities (designing, prototyping, building, marketing, etc.) involving multiple artifacts (workplaces, tools, machines, forms, etc.). In the same way, the experience of using a refrigerator or running a piece of software involves 
human bodies engaged in an array of recurrent activities (shopping, loading, retrieving, balancing, etc.) involving multiple artifacts (kitchens, offices, groceries, receipts, bank statements, checks, etc.). From a practice perspective, goods and services both require the coordination of activities, bodies, and artifacts to be produced and consumed. Rather than seeing these as orthogonal, we believe there is analytical value in seeing both as constituted in practice.

Second, services (and goods) are material. As evident in the quotes above, the prior dominant goods-oriented logic was focused on tangible goods and resources, with the new service-dominant logic oriented around intangible resources emphasizing skills and knowledge (Vargo and Lusch 2008). However, the presumption of intangibility in the case of service exchange relative to that of goods obscures the way in which both are material. Importantly, materiality is not the same as tangibility, a distinction not always recognized in the literature. For example, Lovelock and Gummesson (2004) equate intangibility and immateriality (p. 24), and distinguish between "material goods and immaterial services" (p. 25). But the fact that we cannot touch or grasp something (intangibility) does not make it immaterial. Consider, for instance, the entertainment service of viewing a movie in a theater (Barrett and Davidson 2008). This is produced, in practice, by embodied consumers located in a certain physical place and time and through a particular projection method. The service of providing and viewing movies cannot exist without some specific material instantiation. Even though projected images may appear to be intangible, this makes them no less material for they only exist in relation to practices that entangle them with phenomena such as theaters, screens, and projectors, as well as time and place. Using this same logic, we would make a similar case for software-based services. While software may appear intangible, it only exists in relation to the particular computers, networks, bodies, and workplaces through which it is produced and used. For software to exist, it has to be enacted in some form-minds, computers, code, specifications, etc. As Introna (2011, p. 116) notes, to act in the world requires "material enactment." Thus, to be real, both goods and services have to be materialized in practice.

Third, the materialization of services (and goods) is performative. The specific activities, bodies, and artifacts that are engaged in producing and consuming services are not passive mediators or neutral channels for developing and delivering the intangible essence of the service. On the contrary, what the service is, at any given time and place, reflects the materiality involved in its constitution in practice (e.g., equipment, media, channels, bodies, buildings, spaces, etc.).
For instance, returning to our movie example, the kind of camera used to shoot the movie (one for professional film making or one to record home movies) makes a difference to the movie viewing experience, as do the specificities of how the movie is being projected (in a theater or streamed through the Internet to a mobile device). Indeed, even a cursory review of the history of film production reveals how significant the material capabilities of film, cameras, studios, directors, scripts, actors, projectors, theaters, VCRs, DVDs, video streaming, etc., have been to both the production and consumption of movie entertainment. Remove the film, cameras, studios, directors, scripts, actors, projectors, theaters, VCRs, DVDs, or video streaming from the practice, and you no longer have a service that is recognizable as movie entertainment. Similarly, the quality and operation of software depend critically on the material capabilities of the activities, bodies, and artifacts involved in its production and use. The specific materialization thus matters to the service that is developed and delivered; it is performative. While the notion of "performance" refers to the doing of an activity (e.g., the playing of the piano), the notion of "performativity" refers to the outcomes produced by the doing (e.g., uttering the statement "You're fired" in certain circumstances generates a termination of employment) (Austin 1962; Barad 2003). Uttering the statement "You're fired" is a specific material enactment because to have effect it requires utterance by an actualized authority capable of its realization. That is, not anybody uttering this statement will produce the reality of terminated employment. Only someone (e.g., a manager) with hierarchical authority within the institution will have that capacity. In the same way, the specific material enactments of services (and goods) are consequential for the outcomes that are produced; they are performative.

Seeing services as materially enacted in practice requires recognizing materiality as inseparable from the constitution of everyday life. A number of scholars have been advocating the importance of artifacts and technology in producing services for some time. For example, studying the processes of ship navigation, Hutchins (1996) has argued that artifacts are an integral part of an extended cognitive system that is embedded in action and memory and that is (re)configured in response to situated action. Studying financial services, Knorr Cetina and Bruegger (2002) have highlighted the materiality of the screen world with which financial traders engage to perform market deals through electronic communication. Thrift (2004) has proposed the notion of a "technological unconscious" to draw attention to the way that life is (and has been) influenced by a technological milieu as far back as the domestication of fire (see also Hayles 2006; Mackenzie 2006). Drawing on Haraway's (1997, p. 11) 
notion of "materialized figuration," Suchman (2007, p. 227) has advocated "interventions into current practices of technology development" with a view to "critical consideration of how humans and machines are currently figured in those practices and how they might be figured - and configured differently." Reconceptualizing service as materialized in practice thus affords valuable analytic purchase on how we understand the production and influence of services in practice.

We propose a relational and practice-based approach on the grounds that such a move reframes questions in a way that threads through the multiplicity and performativity of activities, bodies, and artifacts involved in generating and experiencing service. Indeed, we argue that by focusing our attention on practice, we are able to see how services are deeply and inescapably configured by their specific materializations in particular times and places. This approach would appear to be particularly important given the increasing digitization of services and the growing dependence on technologies, data, and infrastructures that this entails (Tilson et al. 2010). Effective understanding of digital services and their consequences will require conceptual tools that take materiality seriously in studies of service innovation. We believe that the recently emerging sociomaterial perspective in studies of organizations and information systems may offer a promising approach for doing so.

\section{Exploring Sociomateriality}

There are many different theoretical hues within the broad category of approaches that adopt a relational approach to the question of technology. Actor-network theory (Callon 1986; Latour 1992, 2005) is the most well-known of these, and a substantial body of work has been generated within this area. Other approaches include Pickering's (1995) mangle of practice, Knorr Cetina's (1997) object-centered sociality, and Latham and Sassen's (2005) digital formation. Sociomateriality is a more recent approach (Mol 2002; Suchman $2002,2007)$ with interest growing in its application to information systems. To date, there have been only a limited number of papers published that explicitly engage with this lens (see Introna and Hayes 2011; Leonardi and Barley 2010; Nyberg 2009; Orlikowski and Scott 2008; Styhre 2010; Yoo 2010). Working within this approach, we draw specifically on insights from the field of technoscience and the contributions of Karen Barad (1998, 2003), which are most fully developed in her 2007 book, Meeting the Universe Halfway. After a necessarily précised account of a few of
Barad's complex ideas, we will engage them in the task of unpacking two key aspects of online digital service innovations that are currently gaining considerable prominence: the algorithm and the crowd.

Barad (2007) proposes "agential realism" as her conception of world making, in which the basic unit of reality is the phenomenon, consisting of intra-acting - rather than the more typical interacting - agencies. As Schrader (2010, p. 283) observes,

In contrast to interactions that suggest connections between independent entities, intra-actions draw attention to the inseparability of individual (human or nonhuman) agencies, conventionally called "subjects" and "objects," "bodies" and "environment" prior to experimental enactments. Independent of specific material meaning-making apparatuses, [phenomena] remain indeterminate.

Thus, agents, things, or concepts cannot be understood as having determinate boundaries, properties, or meanings prior to their encounters. Rather, they remain ontologically indeterminate and are only constituted through particular entanglements. These entanglements consist of ongoing intra-acting agencies (causal relations), which do not exist a priori as ontological units but emerge relationally, resulting in "marks on bodies," that is, outcomes that make a difference. Barad regards observable differences - or, as Rouse $(2004$, p. 12) describes them, "material indications of phenomena"-as effects of a particular set of practical performances.

For Barad, practices always entail both meanings and materialities, and she signals this with the term materialdiscursive. Importantly, she is using the term discourse in a distinctive way: "Discourse does not refer to linguistic or signifying systems, grammars, speech acts or conversations... it is that which constrains and enables what can be said" (2007, p. 146). The notion of material-discursive shifts the traditional focus on language and representation toward recognizing that discourse necessarily entails materialization in some form. Discourse and materiality are mutually constitutive. Applied to services, the sociomaterial perspective focuses our attention on the material-discursive practices that produce the service. From this perspective, services and service innovations are contextually situated and performative. This encourages us to examine how services are materialized in particular times and places through particular practices, and how this ongoing enactment configures specific boundaries, properties, meanings, and differences, and with what implications. 


\section{Explicating the Materialization of Service in the Hospitality Sector}

One particular service arena that has experienced considerable innovation in service design and delivery is that of hospitality. Phenomena within hospitality epitomize many of the key characteristics of service as they are particularly tied to relational dynamics and situated performances. A service within the hospitality sector, such as an overnight hotel stay or dining in a restaurant, necessarily involves the producer and consumer in a detailed engagement during the service experience. Indeed, as Chesbrough and Spohrer (2006, p. 37) note about services,

The services transaction is different. The exchange is co-generated by both parties, and the process of adoption or consumption is an integral part of the transaction. So often the adopter is co-producer, intimately involved in defining, shaping, and integrating the service.

Sociomateriality offers a particularly evocative way of thinking about hospitality services because it fundamentally repositions service from an interaction between two entities, known in advance, that come together to engage in some kind of exchange to a relational intra-action through which subjects and objects (thus further relationships and dependencies) emerge through their encounters with one another. For example, consider the service experience of restaurant dining. Far from being a simple transaction involving the interaction of a provider and consumer, it entails a set of complicated and dynamic power relations that differentially configure us as respected guests, paying customers, discerning palates, demanding consumers, victims of the maître d's dictates, and stakeholders in the local economy. The enactment of such processes is always threaded through a time and place involving seasons, cuisine, views, and settings.

If we make a cut through the entanglement of contemporary hospitality, we find that it has recently been transformed by a particular set of sociomaterial practices that have come to characterize travel routines involving the Internet-from search engines, web portals, intermediaries, and aggregators to online reviewing and ranking schemes that rely on usergenerated content. The digital provision of travel information is a fast-growing and increasingly significant arena within the hospitality sector. We have been examining the nature and influence of online user-generated content within this sector, and focusing in particular on the role and implications of the TripAdvisor website (Scott and Orlikowski 2012a, 2012b).

TripAdvisor is the largest travel website in the world, hosting over 125 million user-generated reviews and opinions on over
3.1 million businesses (including hotels, restaurants, and venues) in more than 134,000 destinations worldwide. ${ }^{2}$ The reviews and rankings provided by TripAdvisor members are used by travelers to "plan the perfect trip." These also serve as "infotainment," enhancing and extending the practice of travel. Casual browsers of the TripAdvisor website are shocked and pleased to learn about the experiences of others guests, picking up tips that help them to book the best rooms as well as learn about points of local and/or special interest that inform preparations for their trip. Purposeful users draw on the multiple reviews, ratings, and rankings provided on TripAdvisor and include them as part of a plurality of sources that they refer to before booking their travel. Indeed, research has found that user-generated reviews can and do influence travelers' purchasing decisions (Starkov and Price 2007; Vermeulen and Seegers 2009). As members of TripAdvisor, users may post their own reviews online, providing accounts of their personal guest experiences in specific terms and details.

TripAdvisor is an instantiation of "service logic" through which "customers use resources made available to them in usage processes, where the use of these resources renders value for them" (Gronroos 2011, p. 240). In turn, the practice of posting online reviews provides the flow of input that enlivens TripAdvisor services by generating data for the databases, ranking algorithms, member preferences, and reputational mechanisms through which contributions are graded, sorted, manipulated and rendered visible on the website.

To explore the specific materializations of the TripAdvisor service in practice, consider the vignette box below, compiled from our research field notes to ensure anonymity of our sources.

In this vignette, we see how the services of hospitality - both that of travelers reviewing and ranking hotels, and that of hoteliers servicing their guests-are realized through material-discursive practices. Among these are the sifting of the algorithmic search engine, the specific guest experience conveyed by traveler photos, the order in which the automatically cross-referenced weblinks are used, the practice of opening several websites simultaneously, the TripAdvisor ranking mechanism that displays the most popular hotels in a given region, the user priorities that are created during the search process, as well as working through the broken printer during check-out. The reconfigurations enacted in the process revise boundaries, change meanings, and alter properties, conditioning the performance of all those involved.

\footnotetext{
${ }^{2}$ http://www.tripadvisor.com/PressCenter-c4-Fact_Sheet.html (retrieved December 23, 2013).
} 
Molly is seeking a place to stay in Boston for an upcoming trip. A web search activates the Google algorithmic search engine to sift through billions of entries in its indices, producing page after page of websites that review and rank hotels. Hotels that have paid for a sponsored link come first, then those that have the most cross-referenced links, the most frequently visited. If a hotel has a website, it appears as a whole entry on the Google page; if it doesn't, then its name only appears in bold within other listings (including references to TripAdvisor reviews). Molly clicks on the first ten links, disregarding hotels without a webpage. She pulls up four home pages, cross-checks the prices that they have posted with two travel intermediary websites, then clicks through to the TripAdvisor website. In the "town/ city" box, under the banner "Find Hotels Travelers Trust" she types "Boston." TripAdvisor's Popularity Index produces a ranked list of hotels in the Boston area. Molly reads through the reviews, clicking the "helpful" button if the review is informative, disregarding those that are badly written, plain rude, or posted by people to whom she doesn't relate: "They obviously don't travel much nor do I care as much about the art on the wall," she thinks to herself. Having spent longer than intended on the reviews-entertained by the posting in which a member complains about housekeeping for walking in at an awkward moment, annoyed by another in which a tirade is prompted solely by a waiter dropping a fork at dinner-Molly notes how highly the hotel that appeals to her is ranked and browses through photos of the hotel posted by members. The reviews for this hotel, The Somerton, speak to her concerns and are backed up with photos, links and helpful hints. It sounds like her "thing"-close to the places she wants to visit, small/boutique, and trendy but with some facilities for kids. This hotel (and the few others she read about) will appear in the "Recently viewed" box that appears when she returns to the website. Molly needs to book by the weekend but, if she has time, she will ask her East Coast friends if they know the Somerton Hotel or know someone who does. If they can come up with local knowledge that trumps that on TripAdvisor she'll reconsider, otherwise the reviews and high ranking on TripAdvisor have persuaded her.

The next day at work Molly's email pings, she glances up and sees a message from TripAdvisor (see Figure 1): "Someone's been reading your reviews." The message continues "Hi travel_gem! When you reviewed the Oldebourne House Hotel last month, you probably wondered if anyone would read what you wrote. Well, more than 1,000 travelers have viewed it so far. You've definitely made a difference. Thank you. Would you like to review another place you've been? Your audience is waiting..." Molly smiles, and raises an eyebrow at the thought of her reviews influencing other travelers. She decides that if the kids get to sleep on time this evening maybe-since her "audience is waiting"-she'll write up an overdue review of the Blu Hotel, the most recent hotel where she stayed. If she were to stay there again, she would ask for a room overlooking the square rather than the garage. Other travelers should also know that the hotel is on a flight path: "That wasn't on the hotel homepage, now was it?"

At the Somerton Hotel in Boston, the manager, Carl, is holding his weekly staff meeting. After working through a number of items on his agenda, Carl pulls up the hotel's TripAdvisor listing on his laptop for everyone to see. He congratulates housekeeping-Monisha and Stella - for the positive comments received. There is an awkward pause. The receptionist, Mandy, says she would like to talk through the negative comments posted about her online: "Hotel was beautiful but the disheveled receptionist couldn't print our bill. She seemed more concerned about her chipped nail than helping us to check out so that we could get to the airport on time and was really rude." Mandy says in an embarrassed tone, "I was having a bad day. I hurt my hand pulling the printer out from under the desk to see if I could fix it. I wasn't trying to be rude but nothing was working. It wasn't about my nail varnish being chipped!" Back in his office, Carl puts a call in to the technical team to fix the reception printer, and adds bonuses to the payroll for Monisha and Stella to reward them for their positive mentions. Mandy had gone back to reception reassured that the comments about her were put in context, but Carl could tell it was still weighing on her mind and he worried that this would further distract her. Hotel employees have become terrified of getting a bad review.....Before leaving for the day —and even though he tries not to look more than once a week-Carl can't resist checking the Somerton's ranking on TripAdvisor once again.

After returning from her trip to Boston, Molly is finishing up some work on her home computer, when she receives two member update emails from TripAdvisor (see Figures 2 and 3). She notices a badge next to her pseudonym "travel_gem"-that indicates she has been promoted from a white to a green star. The text next to it says: "Your Contributor badge tells the TripAdvisor community you're a regular reviewer. Plus, you've received 5 helpful votes from the community. Got more to say? We'd love to hear it!" Molly leans back in her chair: "Ha! Well here is another one for you," she smiles and uploads her review of the Somerton Hotel. Having met the criteria of the content management algorithm, it becomes data for displaying on the website and inputting to the Popularity Index. When the database in Newton, Massachusetts (the headquarters of TripAdvisor), refreshes its computation, the Somerton Hotel's position in the ranking of Boston hotels is poised to change. 


\section{Someone's been reading your reviews}

Hi travel_gem,

When you reviewed the Oldebourne House Hotel last month, you probably wondered if anyone would read what you

wrote. Well, more than 1,000 travelers have viewed it so far. You've definitely made a difference.

Thank you.

Would you like to review another place you've been?

Your audience is waiting....

Write a new review

Figure 1. Email from Trip Advisor Regarding Specific Review

\section{Subject: People love your reviews}

Congratulations! Come see your badge.

Thank you! Your 13 great reviews helped us get here!

Your Contributor badge tells the TripAdvisor community you're a regular reviewer. Plus, you've received 5 helpful votes from the community.

Got more to say? We'd love to hear it!

Write a review.

\section{Reviewer}

3-5 reviews

\section{Senior Reviewer}

6-10 reviews

\section{Contributor}

11-20 reviews

\section{Senior Contributor}

21-49 reviews

\section{Top Contributor}

50+ reviews

Meet some of our top contributors from around the world. These members have seen and done it all-and shared hundreds of their opinions on TripAdvisor.

Read their stories.

\section{Figure 2. Email from Trip Advisor Regarding Member Update}




\section{Subject: Your review update from TripAdvisor}

Someone's been reading your reviews

Your opinions have made a real difference. Thank you!

Your recent reviews

\section{REVIEW}

Oldebourne House Hotel

King Leopold Cafe

Blu Hotel

The Merrimac Inn

$\underline{\text { Review another place }}$

Your readers

$72 \%$ of your readers are in United Kingdom

$11 \%$ of your readers are in Greece

$5 \%$ of your readers are in Israel

$12 \%$ of your readers are in other countries

About you

MEMBER NAME

MEMBER SINCE

LOCATION

TOTAL REVIEWS

BADGE LEVEL travel_gem

August 2, 2009

Louisiana

13

Contributor
TOTAL READERS*

1,136

33

22

11
HELPFUL VOTES

DATE

June, 2011

June, 2011

June, 2011

June, 2011

Write 8 more reviews to earn your next badge

TOTAL READERS*

TOTAL HELPFUL VOTES

$\underline{\text { Update your info }}$

*"Total readers" includes everyone who has seen your TripAdvisor reviews during the past 12 months.

Figure 3. Email from Trip Advisor Regarding Member Review Update

While the vignette about Molly's experiences and the examples in Figures 1-3 are discursive - they could be read primarily as language-based narratives - we argue that conceptualizing them as part of a sociomaterial entanglement that is constitutive in practice produces different insights. Molly's engagement with TripAdvisor is configured by her pseudonymous travel_gem identity on the system and the way the system displays certain things in certain ways on her screen depending on her profile details (location, contributor status, etc.). The reviews that Molly/travel_gem submits are configured by the options the system makes available: six specific categories (value, location, sleep quality, rooms, cleanliness, service) to be rated on a five-point scale, a freetext box for open-ended comments, and the ability to upload photos. Similarly, the data sent by TripAdvisor to Molly/ travel_gem have been materially configured by the algorithms analyzing trends in TripAdvisor's review database. These have been automatically rendered into email messages to visually highlight Molly's/travel_gem's reviews and their influence in relation to other reviews and users of the website.

Our findings show that services and service innovations cannot be realized without processes of materialization that draw together and thread through tangibility and intangibility, 
agency and structure, words, things, and deeds. Experiencing hospitality through the situated practice of travel is entirely entangled with the materialization of service. The quality of service encounters - what makes each one differentdepends upon intra-action and specific boundary-making material-discursive practices. So, for example, when Molly was booking travel she wanted facilities for kids included, but was not bothered by the art on the walls. When she stayed at a hotel, the noise from the flight path mattered to her, but it might not to others. Carl makes the positive response to housekeeping an occasion for additional rewards, while the negative comments elicit specific remedies to fix facilities and reassure demoralized staff.

If we call out the entanglement of material-discursive practices instantiated in Figure 3, we find that TripAdvisor not only tells travel_gem that she has made a difference but also gives her grounded evidence of relationality: her review practice is engaging travel_gem with travelers "around the world," she is part of some "thing" that has resulted (so far) in millions of reviews. She feels that she is leaving something behind, a "contribution" that goes on performing, long after she has stayed at the hotel or entered her review on the TripAdvisor webpage, and that not only changes minds but influences booking decisions and ratings. Through her practices, she is making a "material difference" to the priorities that are created during the search process, the position of the hotel on the Popularity Index, the service experience of other travelers, and the enactment of hospitality by hotel staff. By computing and displaying Molly's engagement with the website and the response of others to her reviews, TripAdvisor works to solicit more contributions from users such as Molly. By using member activity data in the design of their reputation lever, TripAdvisor attempts to mitigate the tendency for people in the crowd to use anonymity as a cloak for potentially offensive graffiti-like statements (Levmore 2011) and a particular kind of (unverified) accountability in their review practices.

In the travel practices highlighted above, there were many sources and forms of information, but we can say that the format of TripAdvisor proved pivotal and became integral to the formulation of knowledge enacted. The expectations and experiences of travelers such as Molly and hotel staff such as Carl, Monisha, Stella, and Mandy are thoroughly entangled with the material-discursive practices that constitute online systems such as Google and TripAdvisor. Such systems are deeply dependent on two key elements that have enabled the service innovations underlying web services and social media: automated computations (algorithms) and large numbers of users (crowds). As Fishkin (2010) notes, "The collective 'users' of the Internet (The Crowd) create, click, and rate, while mathematical equations add scalability and findability to these overwhelming quantities of data (The Algorithm)." We turn now to a consideration of these two elements.

\section{Considering Algorithms and Crowds}

A number of scholars have begun to examine the implications of increasing dependence on algorithms and crowds for the production and delivery of services. For example, Galloway (2006) characterizes these developments as the rise of "algorithmic culture," while Lash (2007) writes about "algorithmic power." Beer (2009, p. 990) examines the "increasingly powerful and active technological environments that operate without the knowledge of those upon whom they are taking an effect"- environments that Thrift (2004, p. 187) refers to as "performative infrastructures." Such phenomena are particularly difficult to study, as Graham (2005, p. 576) indicates:

Given the inevitably confidential, proprietary and highly technical nature of the core algorithms that now socially sort so many key social domains, what research techniques and paradigms can offer any genuine assistance here? Clearly, the research challenges here are considerable.

We believe that notions of sociomateriality may be particularly helpful here.

\section{Algorithms}

Algorithms are a set of step-by-step instructions to achieve a desired result in a finite number of moves. Algorithms act; they do things. They form the basic ingredient of all computer programs, telling the computer what specific steps to perform in what specific order with what priority or weighting so as to accomplish a specific task, such as computing taxes or retrieving data about a customer. Common algorithms in use today perform tasks such as calculating, coding, classifying, filtering, finding, optimizing, ranking, rating, routing, scheduling, searching, sorting, storing, and verifying. Algorithms are increasingly performing most online service innovations, and thus it is useful to consider the entailments of their constitutive role.

Zysman (2006, p. 48) has argued that the rise of algorithms in service innovation represents what he calls "the fourth services transformation." He maintains that after phases that saw financial engineering, changes to consumer and business purchasing, and the conversion of unpaid, typically femaledominated occupations into commercial services, we now have a "fourth service story" centering on digital or algorithmic transformation: 
Service activities themselves are changed when they can be converted into formalizable, codifiable, computable processes with clearly defined rules for their execution. This is an algorithmic service transformation facilitated by IT tools (p. 48).

A body of literature on the implications of algorithms for organizing is emerging, for example the enactment of "algorithmic configurations" explored by Callon and Muniesa (2005) in the marketplaces of financial services - forms of ordering work that are enacted by the distributed and mutually constituting calculative agencies of humans and technologies. Work by Mackenzie (2006) highlights that while many possible orderings and actions may be encoded, for any given situation a specific algorithm expresses and reinforces one ordering at the expense of others. While algorithms are often considered mathematically and formally, this abstraction is artificial and temporary because it is practice that enlivens algorithms and activates their consequences. Such an understanding directs our analysis to the definitional and boundarymaking implications of algorithms as performed in practice in specific times and places. As Mackenzie notes,

code as expression and code as action never coincide fully...code, the material that lies at the core of software, is unstable because it is both expression and action, neither of which are materially nor socially stable. In saying something, code also does something, but never exactly what it says, despite all its intricate formality (p. 177).

A sociomaterial perspective helps us see the performance of algorithms as configuring online services through the material-discursive practices that include some things and exclude others, and which make some things explicit and others not. As Hodder (2009) writes,

The ethical issue with algorithms and information systems generally is that they make choices about what information to use, or display or hide, and this makes them very powerful. These choices are never made in a vacuum and reflect both the conscious and subconscious assumptions and ideas of their creators.

Drawing on Amazon as an example, Hodder points to the various algorithms used to classify, rank, sort, and recommend products. She argues that these technologies are substantively shaping the service landscape experienced by consumers:

Amazon is using algorithms, which rely on their classification system, with various statistics like "Sales Rank" to rank products in search results on the site. These algorithms and classifications have points of view.

Returning to our example, TripAdvisor's website currently hosts over 125 million reviews and opinions, which serve as input to TripAdvisor's primary algorithm, the Popularity Index. For each hotel, TripAdvisor posts all of the user reviews and ratings produced for that hotel, along with that hotel's ranking on the Popularity Index. This numerical ranking is a calculated score that rank orders all hotels within a geographical region. While Google made its initial PageRank search algorithm public (it was part of a Stanford doctoral dissertation), it has subsequently incorporated hundreds of additional criteria for determining page rankings, all of which are now kept secret for competitive reasons as well as to deter people attempting to game the results. ${ }^{3}$ Similarly, TripAdvisor does not disclose the details of its Popularity Index, simply noting on its website that this proprietary algorithm "incorporates traveler ratings to determine overall traveler satisfaction."

Algorithms require that the items being compared are commensurable, standardized with stable and defined properties that make comparability and calculation possible. User reviews on TripAdvisor are both subjective and idiosyncratic, reflecting the personal experiences with hotels that make their insights so valuable to fellow travelers. By definition, the Popularity Index ignores these subjective reviews, focusing instead on user ratings, the quantitative score (out of five) given by users to six categories, the meaning of which is not defined. Ironically this ranking only draws attention to the interdependencies at work; the temporary order brought about by the ranking algorithm produces a particular point of view or boundary-making cut on the phenomenon. This eradicates idiosyncrasies and conflates differences in user reviews, algorithmically enacting a standardized view that excludes vital relationships and context details that help make sense of the review as part of the process of travel.

Striphas (2010) notes that by nature of how algorithms work - through quantification and aggregation - the results produced exist "at least one level of abstraction beyond the [activities] that first produced the data." He suggests that this opacity generates "a deceptive aura of objectivity." Indeed, part of the power of rankings is their capacity to present themselves as objective fact. They intimate that they represent the truth. TripAdvisor's slogan, for example, is "Get the Truth, Then Go." It describes its ranking algorithm on its

\footnotetext{
${ }^{3}$ http://en.wikipedia.org/wiki/Google_Search (retrieved July 5, 2013).

${ }^{4}$ http://www.tripadvisor.com/help/how_does_the_popularity_index_work (retrieved July 5, 2013).
} 
website as follows: "Unlike other sites that simply rank a hotel by price or hotel class, our Popularity Index truly reflects what real travelers...are saying." As with other online service providers, TripAdvisor keeps the ranking algorithm confidential. In this way, as Roberts (1991, p. 359) observed, it "manages to impose its way of seeing, without being able to be seen" [emphasis added].

To the extent that more and more online services rely on usergenerated content that is manipulated algorithmically, the general lack of transparency of algorithms is problematic. It shifts the forms of influence and power that are performed by algorithms (Lash 2007). Striphas (2010) refers to these developments as the "black box of algorithmic culture":

In the old cultural paradigm, you could question authorities about their reasons for selecting particular cultural artifacts as worthy, while dismissing or neglecting others. Not so with algorithmic culture, which wraps abstraction inside of secrecy and sells it back to you as, "the people have spoken."

In a similar critique, Kevin Slavin, a computer game designer, has commented on the "algoworld, the expanding space in our lives that's determined and run by algorithms." As he noted in his recent TED talk (2011),

We're writing things that we can no longer read and we've rendered something illegible and lost the sense of what's actually happening in this world that we've made.

But as Introna (2013, p. 14) reminds us, the issue of what algorithms do lies not with the details of the algorithms in isolation, but in their incorporation within specific sociomaterial practices.

\section{Crowds}

Social media would not function without the active participation of millions of users who contribute content, a practice that is often termed crowd-sourcing. The algorithms constituting systems such as Amazon, Netflix, TripAdvisor, and YouTube are intimately dependent upon large numbers of individuals acting in particular ways, for example, creating and viewing content, rating and recommending content, etc. This "crowd" has drawn the attention of commentators, many of whom refer to collective creativity or "wisdom of the crowd" (Benkler 2006; Jenkins 2006; Surowiecki 2004). While the term crowd typically evokes a nameless group of people in close proximity such as one may encounter in a football stadium, the notion of the crowd in this context differs from it in many ways. It also differs from the term mass market, often evoked to describe a large general group of consumers. In contrast, the crowd implicated in usergenerated content websites and online service provision refers to the distributed, online, virtual, diverse, anonymous/ pseudonymous, and fluid set of individual participants whose engagement with a website is materially configured by the algorithms at work on that site. This crowd is constituted by the material-discursive practices of both the website participants and those of the website provider. It is a performative, material enactment that produces and consumes certain forms of user-generated content.

In the case of TripAdvisor, the crowd is constituted by the more than 57 million members who have posted the more than 125 million reviews. This crowd has played (and continues to play) a vital role in the success of the TripAdvisor service innovation within the hospitality sector. The crowd's ongoing contributions, both as producers of content (traveler reviews and opinions) and as providers of revenue as they click on links that supply an income stream to the company, maintain the viability of the TripAdvisor service. Indeed, member points of view are both featured and favored, and this is reflected in TripAdvisor's mission, "enabling travelers to plan and have the perfect trip." As one of the hoteliers in our study observed, TripAdvisor is a service "by travelers, for travelers."

Whether they are casual or active members of TripAdvisor, all of the information posted by users (subjective ratings and reviews) serves as input to the website's algorithms, which filter, manipulate, compute, and render the content into the form that is visible online. TripAdvisor's click-through business model depends upon user-generated content to draw commercially valuable traffic to the website, facilitating opportunities for these users to click on links that lead to other travel websites (such as Expedia, Hotels.com, Booking.com, and Hotels4U) where additional information and booking engines support the actual purchase of travel products and services. In this sense, people engaging with TripAdvisor are in a deeply relational practice as "con-ducers"-producers and consumers that promote and emote-actively helping to bring social media into being as well as helping to ensure its value over time.

Describing this emergent notion of the crowd, Van Dijck (2009, p. 54) has observed

When Time hailed You as the "Person of the Year," the magazine paid tribute to the millions of anonymous, productive contributors to the web-a tribute akin to the badge of honour bestowed upon the unknown soldier. This powerful but contrived 
metaphor has come to define the concept of user agency as it dissipated into academic and professional discourses.

The notion of user agency has been framed as participatory engagement, in contrast to the passive recipients of earlier media (Jenkins 2006). However, as van Dijck (2009, pp. 43-44) observes, this is misleading, as not all in the crowd are active contributors. Indeed, surveys suggest that only about 13 percent of participants in online systems make contributions, while the rest are passive recipients of content provided by others (van Dijck and Nieborg 2009). Given participation is increasingly regarded as a viable basis for action, chosen over formal expertise as a basis for reconfiguring practice, it is important to understand more carefully what constitutes it, how it is performed, and with what implications.

As we saw above, the algorithms designed and deployed on these websites play a powerful role in constituting the kinds of practices that may be enacted by the crowd. They shape the materialization of TripAdvisor's service for its users. Van Dijck (2009, p. 43) advocates problematizing the notion of users as primary "creators and arbiters of media content," and asking "what role do platform providers play in steering the agency of users and communities?" Content management practices, database designs, algorithms, network structures, etc., all serve to configure particular services and outcomes. Furthermore, the crowd does not just "generate content" for public display on the website. Perhaps even more importantly, in the contemporary online service world, these users are (often unwitting) providers of digital data to the website, as van Dijck $(2009$, p. 47, 49) argues,

[I]t is crucial to understand the new role of users as both content providers and data providers. Besides uploading content, users also willingly and unknowingly provide important information about their profile and behaviour to site owners and metadata aggregators. Before users can actually contribute uploads or comments to a site, they usually have to register with their name, email address and sometimes add more personal details such as gender, age, nationality or income. Their subsequent media behaviour can be minutely traced by means of databots. More importantly, all users of UGC [usergenerated content] sites unwittingly provide information because IP addresses - the majority of which can be connected to a user's name and address - can be mined and used without limit by platform owners....[And] the bottom line is that users have no power over data distribution.

Accounting for the dynamics of the crowd in studies of service innovation would thus need to consider the material- discursive practices of content generation and distribution, the role and performance of algorithms in shaping these practices, and the mechanisms through which digital data on user behavior is captured, stored, and used to inform further automated processes, whether customization, recommendation, observation, or tracking.

\section{Implications}

In this paper, we have emphasized the importance of understanding service as constituted in practice through specific materializations that configure activities, bodies, and artifacts in particular ways in particular times and places. We have suggested that sociomateriality may offer a useful lens for exploring such materiality and performativity, particularly as service innovations become more pervasive and influential in contemporary organizations. We considered this in the context of online rating and reviewing systems, examining how crowd-sourced content is configured by algorithms to shape actions, decisions, management, and changes that become manifest in practice. We focused on examples in the hospitality sector, looking at how the specific material enactments of hotel reviewing and rating on TripAdvisor made a difference to the performance of service on the ground within hotels.

Theories are lenses that focus us on one thing rather than another and sociomaterial approaches have risen in importance because they put capacity for action and entanglement in practice on our agenda. As we saw in the example of Molly's reading and contributing of hotel reviews, these practices are configured by the TripAdvisor system. By making the turn to material-discursive practices, we recognize that what we are studying is always materialized in practice, and that specific materiality makes a difference to what is enacted. Such an approach challenges us to reframe our research questions to include the specific sociomaterial conditions in which service innovations take place. Studying practices is always challenging and requires time-consuming ethnographic inquiries in the field. The "inscrutability and executability" (Introna 2013) of online practices involving algorithms and databases creates two further challenges. First, they are typically not available for study. Second, separating them out and analyzing them in isolation does not help us to understand their performativity in practice. Nevertheless we can and should analyze them in sociomaterial practice on screens and on the ground.

Our research in the hospitality sector has revealed that online rating and ranking, as performed through the materiality of algorithms and crowds, is entangled with a significant reconfiguration of interests and relations between hoteliers and 
travelers. As expectations and experiences are transformed, they can change power dynamics and economic control. For example, the rise of social media and user-generated content within the travel sector is generating an important shift in power and influence from producers to consumers. Such shifts may effectively be studied by examining how materialdiscursive practices redraw boundaries, changing inclusions/ exclusions, and making a difference in who participates, how, and with what consequences. Such an approach encourages us to call out the materialization of power and interests in practice, rather than confining our research to discourses centered on terms such as "adding value," which sound neutral but seldom are. Attending to how services are materialized and performed in practice may be useful not only for understanding shifts in knowledge, relationships, and power within the hospitality sector, but also for opening up avenues more broadly for future research in information systems and organization studies.

The sociomateriality approach also draws our attention to consequences in practice. Services are not only performed in practice, but they are also performative, making a difference to what is produced, to the relationships and outcomes generated in practice. In the case of TripAdvisor, for example, the algorithm and the crowd are central to its operational success and powerful influence within the travel sector. They are also central, however, to the difficulties the website has experienced in managing the scale of its crowd-sourced content, monitoring the quality of its members' contributions, and having to frequently update its algorithms to remain innovate and competitive. These ongoing efforts by TripAdvisor to alter its services can be seen as material-discursive practices that continue to codify, manipulate, and compute the content on the website. The service produced and delivered by TripAdvisor is an ongoing enactment, entangling and entailing activities, bodies, and artifacts in sociomaterial practices.

The algorithms constituting the online services we interact with everyday - Google, YouTube, TripAdvisor, etc. - don't just search and sort reality, they also create it. However, such algorithms can only codify, quantify, and compute so much. The rest of service overflows this in practice, as we saw in the details of our vignette. Understanding the construction and operation of algorithms as sociomaterial practices can help us investigate these differences and overflows, inquiring into the performative implications of systems that constitute reality through technologies that we cannot see or understand. As van Dijck (2010, p. 74) notes about search engines,

Without a basic understanding of network architecture, the dynamics of network connections and their intersections, it is hard to grasp the social, legal, cultural and economic implications of search engines.
The same applies to the algorithms that actively produce the online services that are becoming more and more integrated into our organizational and personal activities. Much future research work remains to be done to develop a detailed understanding of the constitutive and performative role played by algorithms and the crowd in online service innovation.

Furthermore, the complexities surrounding online services encompassing the algorithm and the crowd intensify relations of timing and placing: not only does user-generated content dynamically refresh databases (e.g., an average of 80 new contributions are posted to TripAdvisor every minute) but situated experiences are shared, achieving an almost global reach. These ongoing reconfigurations amplify dynamics of change that are otherwise enacted through more gradual practices. Indeed intra-action through time-histories, legacies, and memories - is critical to studying materialization in practice. This prompts the question: What kind of realities are emerging in the phenomenon of service? Much future research is needed in this area.

A sociomaterial approach allows us to see that the dynamics of contemporary service innovations are material-discursive practices. Such an approach emphasizes the relationality, materiality, and performativity entailed in the crowd-sourced algorithmic transformations emerging as central in contemporary online service innovation. By focusing on how boundaries are drawn, how phenomena are configured, and what realities are performed, this approach can provide insights into the intimate interdependencies involving the dynamic relationships of algorithms and crowds. Such an analysis can thus offer insights, not into separate entities and their interdependencies, but the dynamic tensions and intra-actions that produce, to make a play on Barad's term, intra-dependencies, which make a difference to the kinds of services and organizational realities that are enacted.

\section{Acknowledgments}

We would like to thank Michael Barrett and Elizabeth Davidson, as well as the associate editor and reviewers who provided constructive feedback on earlier versions of this manuscript.

\section{References}

Austin, J. L. 1962. How to Do Things with Words, Oxford, UK: Clarendon Press.

Barad, K. 1998. "Getting Real: Technoscientific Practices and the Materialization of Reality," Differences: A Journal of Feminist Cultural Studies (10:2), pp. 88-128.

Barad, K. 2003. "Posthumanist Performativity: Toward an Understanding of How Matter Comes to Matter," Signs (28:3), pp. 801-831. 
Barad, K. 2007. Meeting the University Halfway: Quantum Physics and the Entanglement of Matter and Meaning, Durham, NC: Duke University Press.

Bardhan, I., Demirkan, H., Kannan, P., Kauffman, R., and Sougstad, R. 2010. "An Interdisciplinary Perspective on IT Services Management and Service Sciences," Journal of Management Information Systems (26:4), pp. 13-64.

Barrett, M. I., and Davidson, E. 2008. "Exploring the Diversity of Service Worlds in the Service Economy," in Information Technology in the Service Economy: Challenges and Possibilities for the $21^{\text {st }}$ Century, M. Barrett, E. Davidson, C. Middleton, and J. DeGross (eds.), Boston: Springer, pp. 1-10.

Beer, D. 2009. "Power Through the Algorithm? Participatory Web Cultures and the Technological UnconsciousM: New Media \& Society (11:6), pp. 985-1002.

Benkler, Y. 2006. The Wealth of Networks: How Social Production Transforms Markets and Freedom, New Haven, CT: Yale University Press.

Bryson, J., Daniels, P., and Warf, B. 2004. Service Worlds: People, Organizations, Technologies, London: Routledge.

Chandler, J. D., and Vargo, S. L. 2011. "Contextualization and Value-in-Context: How Context Frames Exchange," Marketing Theory (11:1), pp. 35-49.

Callon, M. 1986. "Some Elements of a Sociology of Translations: Domestication of the Scallops and the Fishermen in St. Brieuc Bay," in Power, Action, and Belief: A New Sociology of Knowledge, J. Law (ed.), London: Routledge.

Callon, M., and Muniesa, F. 2005. "Economic Markets as Calculative Collective Devices," Organization Studies, (26:8), pp. 1229-1250.

Chesbrough, H., and Spohrer, J. 2006. "A Research Manifesto for Services Science," Communications of the ACM (49:7), pp. 35-49.

Feldman, M. S., and Orlikowski, W. J. 2011. "Theorizing Practice and Practicing Theory," Organization Science (22:5), pp. 1240-1253.

Fishkin, R. 2010. "The Algorithm + the Crowd Are Not Enough," Rand's Blog, November 29 (http://randfishkin.com/blog/58/ algorithm-crowd-not-enough).

Galloway, A. 2006. Gaming: Essays on Algorithmic Culture, Minneapolis, MN: University of Minnesota Press.

Giddens, A. 1984. The Constitution of Society, Cambridge, UK: Polity Press.

Graham, S. D. N. 2005. "Software-Sorted Geographies," Progress in Human Geography (29:5), pp. 562-580.

Gronroos, C. 2011. "A Service Perspective on Business Relationships: The Value Creation, Interaction and Marketing Interface," Industrial Marketing Management (40), pp. 240-247.

Gustafsson, A., and Johnson, M. 2003. Competing in a Service Economy: How to Create a Competitive Advantage Through Service Development and Innovation, San Francisco: Jossey-Bass.

Gutek, B. A., Cherry, B., Bhappu, A. D., Schneider, S., and Woolf, L. 2000. "Features of Service Relationships and Encounters," Work and Occupations (27:3), pp. 319-351.

Haraway, D. 1997. Modest_Witness@Second_Millennium. FemaleMan_Meets_OncoMouse: Feminism and Technoscience, London, UK: Routledge.

Hayles, N. K. 2006. "Unfinished Work From Cyborg to Cognisphere," Theory, Culture \& Society (23:7-8), pp. 159-166.
Hodder, M. 2009. "Why Amazon Didn't Just Have a Glitch," TechCrunch Blog, April 14 ( http://techcrunch.com/2009/04/14/ guest-post-why-amazon-didnt-just-have-a-glitch/).

Hutchins, E. 1996. Cognition in the Wild, Cambridge, MA: MIT Press.

Introna, L. D. 2011. "The Enframing of Code: Agency, Originality and the Plagiarist," Theory, Culture and Society (28:6), pp. 113-141.

Introna, L. D. 2013. "Algorithms, Performativity and Governability," paper presented at Governing Algorithms: A Conference on Computation, Automation, and Control, New York University, May 16-17.

Introna, L. D., and Hayes, N. 2011. “On Sociomaterial Imbrications: What Plagiarism Detection Systems Reveal and Why it Matters," Information and Organization (21), pp. 107-122.

Jenkins, H. 2006. Convergence Culture: Where Old and New Media Collide, Cambridge, MA: MIT Press.

Knorr Cetina, K. 1997. "Sociality with Objects: Social Relations in Postsocial Knowledge Societies," Theory, Culture \& Society (14:4), pp. 1-30.

Knorr Cetina, K., and Bruegger, U. 2002. "Inhabiting Technology: The Global Lifeform of Financial Markets," Current Sociology (50:3), pp. 389-405.

Lash, S. 2007. "Power After Hegemony: Cultural Studies in Mutation," Theory, Culture \& Society (24:3), pp. 55-78.

Latham, R., and Sassen, S. 2005. Digital Formations: IT and New Architectures in the Global Realm, Princeton, NJ: Princeton University Press.

Latour, B. 1992. "Where Are the Missing Masses? Sociology of a Few Mundane Artefacts," in Shaping Technology, Building Society: Studies in Sociotechnical Change, W. Bijker and J. Law (eds.), Cambridge, MA: MIT Press, pp. 225-258.

Latour, B. 2005. Reassembling the Social: An Introduction to Actor-Network Theory, Oxford, UK: Oxford University Press.

Leonardi, P. M., and Barley, S. R. 2010. "What's Under Construction Here? Social Action, Materiality, and Power in Constructivist Studies of Technology and Organizing," Academy of Management Annals (4), pp. 1-51.

Levmore, S. 2010. "The Internet's Anonymity Problem," in The Offensive Internet: Speech, Privacy, and Reputation, S. Levmore and M. Nussbaum (eds.), Cambridge, MA: Harvard University Press, pp. 50-67.

Lovelock, C. H., and Gummesson, E. 2004. "Whither Service Marketing? In Search of a New Paradigm and Fresh Perspectives," Journal of Services Research (7:1), pp. 20-41.

Mackenzie, A. 2006. Cutting Code: Software and Sociality, New York: Peter Lang Publishing.

Mathiassen, L., and Sorensen, C. 2008. "Towards a Theory of Organizational Information Services," Journal of Information Technology (23), pp. 313-329.

Mol, A. 2002. The Body Multiple: Ontology in Medical Practice, Durham, NC: Duke University Press.

NAE (National Academy of Engineering). 2003. Impact of Academic Research on Industrial Performance, Washington, DC: The National Academies Press.

Nyberg, D. 2009. "Computers, Customer Service Operatives and Cyborgs: Intra-Actions in Call Centres," Organization Studies, (30:11), pp. 1181-1199. 
Orlikowski, W. J., and Scott, S. V. 2008. "Sociomateriality: Challenging the Separation of Technology, Work and Organization," Annals of the Academy of Management (2:1), pp. 433-474.

Pickering, A. 1995. The Mangle of Practice, Time, Agency and Science, Chicago: University of Chicago Press.

Ramiller, N. C., and Chiasson, M. 2008. "The Service Behind the Service: Sensegiving in the Service Economy," in Information Technology in the Service Economy: Challenges and Possibilities for the $21^{\text {st }}$ Century, M. Barrett, E. Davidson, C. Middleton, and J. DeGross (eds.), Boston: Springer, pp. 11-20.

Roberts, J. 1991. "The Possibilities of Accountability," Accounting, Organizations and Society (16:4), pp. 355-368.

Rouse, J. 2004. "Barad's Feminist Naturalism," Hypatia (91:1), pp. 142-161.

Rouse, W., and Baba, M. 2006. "Enterprise Transformation," Communications of the ACM (49:7), pp. 67-72.

Rust, R. 1998. "What Is the Domain of Service Research?," Journal of Service Research (1:2), p. 107.

Rust, R., and Chung. T. 2006. "Marketing Models of Service and Relationships," Marketing Science (25:6), pp. 560-580.

Schatzki, T. R., Knorr Cetina, K., and von Savigny, E. (Eds.). 2001. The Practice Turn in Contemporary Theory, London: Routledge.

Schrader, A. 2010. "Responding to Pfiesteria piscicida (the Fish Killer): Phantomatic Ontologies, Indeterminacy, and Responsibility in Toxic Microbiology," Social Studies of Science (40:2), pp. 275-306.

Scott, S. V., and Orlikowski, W. J. 2012a. "Great Expectations: The Materiality of Commensurability in Social Media," in Materiality and Organizing: Social Interaction in a Technological World, P. M. Leonardi, B. Nardi, and J. Kallinikos (eds.), New York: Oxford University Press, pp. 113-133.

Scott, S. V., and Orlikowski, W. J. 2012b. "Reconfiguring Relations of Accountability: Materialization of Social Media in the Travel Sector," Accounting, Organizations, and Society (37:1), pp. 26-40.

Sheenan, J. 2006. "Understanding Service Sector Innovation," Communications of the ACM (49:7), pp. 43-47.

Slavin, K. 2011. "How Algorithms Shape Our World," TED Talks, July 21 ( http://www.ted.com/talks/lang/eng/kevin_slavin_how_ algorithms_shape_our_world.html).

Spohrer, J., and Riecken, D. 2006. "Services Science," Communications of the ACM (49:7), pp. 31-32.

Spohrer, J., Maglio, P. P., Bailey, J., and Gruhl, D. 2007. “Steps Toward a Science of Service Systems," Computer (40:1), pp. 71-77.

Starkov, M., and Price, J. 2007. "Are Search Engines Becoming Obsolete in the Web 2.0 Frenzy," Hospitality, Hotel \& Travel News, September 17 (http://www.4hoteliers.com/4hots_fshw. php?mwi=2389).

Striphas, T. 2010. "How to Have Culture in an Algorithmic Age," The Late Age of Print Blog, June 14 (http://www. thelateageofprint.org/2010/06/14/how-to-have-culture-in-analgorithmic-age/).

Styhre, A. 2010. "Organizing Technologies of Vision: Making the Invisible Visible in Media-Laden Observations," Information and Organization (20), pp. 64-78.

Suchman, L. A. 2002. "Located Accountabilities in Technology Production," Scandinavian Journal of Information Systems (14:2), pp. 91-105.
Suchman, L. A. 2007. Human-Machine Reconfigurations. Cambridge UK: Cambridge University Press.

Suchman, L. A., Trigg, R., and Blomberg, J. 2002. "Working Artefacts: Ethnomethods of the Prototype," British Journal of Sociology (53:2), pp. 163-179.

Surowiecki, J. 2004. The Wisdom of Crowds: Why the Many Are Smarter Than the Few, London: Abacus.

Thrift, N. 2004. "Remembering the Technological Unconscious by Foregrounding Knowledges of Position," Environment and Planning D: Society and Space (22:1), pp. 175-190.

Tilson, D., Lyytinen, K., and Sørensen, C. 2010. "Digital Infrastructures: The Missing IS Research Agenda," Information Systems Research (21:4), pp. 748-759.

Vargo, S. L., and Lusch, R. E. 2004. "Evolving to a New Dominant Logic for Marketing," Journal of Marketing (68), pp. 1-17.

Vargo, S. L., and Lusch, R. E. 2008. "Service-Dominant Logic: Continuing the Evolution," Journal of the Academy of Marketing Science (36:1), pp. 1-10.

van Dijck, J. 2009. "Users Like You? Theorizing Agency in UserGenerated Content," Media, Culture \& Society (31:1), pp. 41-58.

van Dijck, J. 2010. "Search Engines and the Production of Academic Knowledge," International Journal of Cultural Studies (13:6), pp. 574-592.

van Dijck, J., and Nieborg, D. 2009. "Wikinomics and its Discontents: A Critical Analysis of Web 2.0 Business Manifestos," New Media \& Society (11:5), pp. 855-874.

Vermeulen, I., and Seegers, D. 2009. "Tried and Tested: The Impact of Online Hotel Reviews on Consumer Consideration," Tourism Management (30), pp. 123-127.

Yoo, Y. 2010. "Computing in Everyday Life: A Call for Research on Experiential Computing," MIS Quarterly (34:2), pp. 213-231.

Zysman, J. 2006. "Services Science," Communications of the ACM (49:7), p. 48.

\section{About the Authors}

Wanda J. Orlikowski is the Alfred P. Sloan Professor of Information Technologies and Organization Studies in the Sloan School of Management at the Massachusetts Institute of Technology. She received her Ph.D. from New York University. Her research examines the dynamic relationship between organizations and information technologies, with particular emphases on organizing structures, cultural norms, communication genres, and work practices. She is currently exploring the sociomaterial entailments of social media.

Susan V. Scott is an Associate Professor (Reader) in the Information Systems and Innovation Faculty, Department of Management at The London School of Economics and Political Science. She received a Ph.D. from the Judge Business School at the University of Cambridge. Her research interests include information systems and risk management, electronic trading, post-trade services, organizational reputation risk management, rating, ranking and review mechanisms in social media, business transformation, and global business management. 